\title{
A protein-induced DNA bend increases the specificity of a prokaryotic enhancer-binding protein
}

\author{
Jonathan Dworkin, ${ }^{1}$ Alexander J. Ninfa, ${ }^{2}$ and Peter Model \\ Laboratory of Genetics, The Rockefeller University, N ew York, N ew York 10021 USA; ${ }^{2}$ Department of Biological \\ Chemistry, University of Michigan Medical School, Ann Arbor, Michigan 48109 USA
}

\begin{abstract}
Control of transcription in prokaryotes often involves direct contact of regulatory proteins with RNA polymerase from binding sites located adjacent to the target promoter. Altematively, in the case of genes transcribed by Escherichia coli RNA polymerase holoenzyme containing the altemate sigma factor $\sigma^{54}$, regulatory proteins bound at more distally located enhancer sites can activate transcription via DNA looping by taking advantage of the increasing flexibility of DNA over longer distances. While this second mechanism offers a greater possible flexibility in the location of these binding sites, it is not clear how the specificity offered by the proximity of the regulatory protein and the polymerase intrinsic to the first mechanism is maintained. Here we demonstrate that integration host factor (IHF), a protein that induces a shap bend in DNA, acts both to inhibit DNA-looping-dependent transcriptional activation by an inappropriate enhancer-binding protein and to facilitate similar activation by an appropriate enhancer-binding protein. These opposite effects have the consequence of increasing the specificity of activation of a promoter that is susceptible to regulation by proteins bound to a distal site.
\end{abstract}

[Key Words: Integration host factor; $\sigma^{54}$-RN A polymerase; upstream activation sequence; transcriptional activator]

Received N ovember 25, 1997; revised version accepted January 27, 1998.

The ability of transcriptional regulatory proteins to act at a distance via DNA looping is characteristic of both prokaryotic and eukaryotic promoters (Matthews 1992; Schleif 1992). Over distances less than the persistence length of DNA ( 150 bp), the DNA is relatively stiff, both torsionally and laterally (Wang and Giaever 1988), and looping is typically aided by proteins that bind to specific sequences on the DN A and bend it with a characteristic stereospecificity (Perez-Martin et al. 1994). However, at larger distances, the intrinsic flexibility of the DN A allows the formation of loops in the absence of a DNA-bending protein (Bellomy and Record 1990). These loops, which lack the stereospecificity provided by a specific, protein-induced DNA bend, may result in inappropriate protein-protein contacts. Thus, specific bends may act not only to facilitate correct protein-protein interactions, but also to prevent the stable formation of loops that result in inappropriate protein-protein interactions.

Transcription by prokaryotic RNA polymerase (RN AP) holoenzyme containing the alternate sigma fac-

This paper is dedicated to the memory of Brian Laurence Selsky. ${ }^{1}$ Corresponding author. Present address: Department of Molecular and Cellular Biology, The Biological Laboratories, Harvard University, Cambridge, Massachusetts 02138 USA.

E-MAIL dworkin@biosun.harvard.edu; FAX (617) 496-4642. tor, $\sigma^{54}$, requires contact between an enhancer-binding protein (EBP) bound at upstream activation sites (UAS) and the holoenzyme (Buck et al. 1986; Reitzer and Magasanik 1986; Ninfa et al. 1987). Through an ATP-hydrolysis-dependent mechanism, activation by the EBP transforms the closed complex formed by $\sigma^{54}$-RNAP at the promoter to an open complex permissive for transcriptional initiation (Popham et al. 1989). A DNA loop is thought to facilitate this interaction by increasing the local concentration of the EBP in the vicinity of the RN AP hol oenzyme (Buck et al. 1987; Su et al. 1990; Wedel et al. 1990; Rippe et al. 1997).

Many prokaryotic species, including Escherichia coli, have multiple EBPs with distinct regulatory roles (M orett and Segovia 1993; Kaufman and N ixon 1996). Their specificity is thought to be largely a consequence of binding to a particular associated UAS sequence upstream of their target promoter(s) through a carboxy-terminal DNA-binding domain (Morett et al. 1988). While DN A binding is not essential for activation, mutant EBPs lacking the DN A-binding domain require far higher concentrations and show a loss of specificity (Dworkin et al. 1997; N orth and Kustu 1997).

Integration host factor (IHF), a heterodimeric protein that bends DN A by $>160^{\circ}$, (Rice et al. 1996) binds in the promoter region of many $\sigma^{54}$-dependent operons at a site 
typically located between the promoter and the UAS sites (Gralla and Collado-Vides 1996). The sharp bend generated by IHF is thought to facilitate the interaction between the UAS-bound EBP and the $\sigma^{54}$-RN AP hol oenzyme, particularly at weaker promoters with a lower affinity for the $\sigma^{54}$-RN AP hol oenzyme (Hoover et al. 1990; Santero et al . 1992). This facilitation depends on the specific geometry of the interaction: If the UAS sites are moved so that the EBP binds on the opposite face of the DN A, then IHF inhibits activation (Claverie-M artin and Magasanik 1992). EBPs can activate from templates missing specific UAS sites; however, this activation is weaker than activation from wild-type templates and it is also inhibited by IHF (Claverie-M artin and M agasanik 1992; Dworkin et al. 1997). By contrast, activation by an EBP lacking a DN A-binding domain is unaffected by IHF (Dworkin et al. 1997); thus, IHF-mediated inhibition is presumably the result of EBPs binding to nonspecific (or cryptic) sites that are not appropriately spaced rel ative to the IHF bend and the $\sigma^{54}$-RN AP bound at the promoter.

The hycA and hypA promoters of the formate hydrogenylase system of $\mathrm{E}$. coli are regulated by IHF and the EBP, FhIA. In the presence of nitrate, expression from these promoters is significantly reduced, and strains lacking IHF (carrying a himA mutation) show an increase (three-to fourfold) in transcription from these promoters over wild-type strains (Hopper et al. 1994). In addition, a Pseudomonas putida strain carrying a himA mutation shows increased basal activation of the $\sigma^{54}$ dependent $\mathrm{Pu}$ promoter in the absence of the cognate EBP, XyIR, and this increase was attributed to activation by heterologous EBPs that might be normally inhibited by IHF (Perez-Martin and de Lorenzo 1995). Similarly, we observed that pspA transcription measured under noninducing conditions (using a pspA-lacZ promoter fusion) in a strain carrying a himA mutation, along with a deletion of the gene encoding the associated EBP, PspF, showed a twofold increase over a strain carrying only the pspF deletion (Dworkin 1997). We, as well as the previous investigators, were unable, however, to attribute this increased basal expression to activation by a particular EBP. We therefore decided to examine whether, in vitro, IHF could inhibit activation by a specific heterologous EBP and whether this inhibition would result in an increase in the specificity of transcriptional activation.

\section{Results}

The pspA gene of $E$. coli is transcribed by $\sigma^{54}$-RNAP (Weiner et al. 1991) and is under control of the constitutively active EBP PspF (Jovanovic et al. 1996; M odel et al . 1997). The pspA promoter region contains two binding sites for PspF (Jovanovic 1997), as well as a binding site for IHF (Fig. 1A,B) (Weiner et al. 1995). In vitro transcriptional activation by PspF at the pspA promoter is facilitated threefold by IHF (Fig. 2A, lanes 3,4; see al so Dworkin et al. 1997). We replaced PspF with the heterol ogous EBP N R, of E. coli. Under conditions of nitrogen limitation, phosphorylated $\mathrm{NR}_{1}$ activates transcription at several $\sigma^{54}$-dependent promoters involved in the metabo- lism of nitrogen-containing compounds ( $\mathrm{N}$ infa and $\mathrm{Ma}$ gasanik 1986). While phosphorylated $N_{1}$ can activate transcription at the pspA promoter (Fig. 2A, lane 1), IHF inhibits this activation fivefold (lane 2 ).

This inhibition suggests that $\mathrm{NR}_{1}$ is bound to site(s) in the pspA promoter region that do not result in an appropriate EBP-IHF-RNAP geometry. The ability of N R, to activate at low concentrations ( $<100 \mathrm{~nm}$ ) from templ ates lacking specific $\mathrm{N} \mathrm{R}_{1}$ binding sites has been attributed to its ability to bind to the DNA nonspecifically (Weiss et al. 1992). In addition, since EBPs can act at distances of up to $2 \mathrm{~kb}$ upstream (or downstream) of their target promoters (Buck et al. 1986; N infa et al. 1987), the possible sites are not restricted to those in near proximity to the RNAP bound at the promoter, as is the case for another prokaryotic transcriptional activator, CAP (Busby and Ebright 1994).

In an effort to extend the generality of this observation, we examined the $\mathrm{E}$. coli $\sigma^{54}$-dependent $\mathrm{glnH}$ promoter. The $\mathrm{glnH}$ promoter region contains two strong and two weak binding sites for $\mathrm{NR}_{1}$ as well as an IHF site (Fig. 1A,B) (Claverie-M artin and M agasanik 1991). As has been demonstrated (Claverie-Martin and Magasanik 1991), N R activates transcription from the gl $\mathrm{nH}$ promoter in vitro and this activation is facilitated fourfold by IHF (Fig. 2B, lanes 3,4). By contrast, PspF-dependent activation of the glnH promoter is inhibited 2.5-fold by IHF (Fig. 2B, lanes 1,2). This inhibition suggests that PspF is binding to site(s) that result in a geometry of the EBP-IHF-RNAP interaction that is unfavorable for activation. The $N R_{1}$ and PspF UAS sites are distinct (Fig. 1B) and neither the pspA nor the glnH promoter region contains sequences matching the heterol ogous UAS sites.

When the sequence comprising the IHF site in the pspA promoter is replaced with a sequence lacking an IHF site, both the stimulatory effect of IHF on PspFdependent activation (Fig. 2C, lanes 5-8) and the inhibitory effect of IHF on $\mathrm{NR}_{1}$-dependent activation (Fig. $2 \mathrm{C}$, lanes 1-4) are el iminated. Thus, IHF inhibition of $\mathrm{NR}_{1}$ dependent pspA transcription is not a consequence of binding site competition or protein-protein interaction between IHF and $\mathrm{NR}_{1}$.

The opposite effects of IHF on activation by two different EBPs at a single promoter suggest that IHF could help determine the specificity of activation. That is, in addition to the specificity resulting from EBP binding to a cognate UAS, the bend generated in the promoter region by the binding of IHF would prevent activation by EBPs bound nonspecifically. We examined this question using in vitro transcription reactions containing multiple templates with different promoters. In the absence of IHF, the EBP N R, activates transcription from promoters containing either PspF-specific (pspA) or $\mathrm{N} \mathrm{R}_{1}$-specific (gl $\mathrm{nH}$ and glnA) binding sites comparably (Fig. 3A, Iane 1). We take as a measure of specificity the ratio of appropriate to inappropriate transcripts, which, in this case (no IHF), is the ratio $\mathrm{glnH}: \mathrm{pspA}=1.6: 1$. In the presence of IHF (lane 2), however, this ratio increases tenfold to $15: 1$. This increase is a result of IHF acting both to facilitate $\mathrm{NR}_{1}$-dependent activation of $\mathrm{glnH}$ and to in- 


\begin{abstract}
Figure 1. Organization of $\sigma^{54}$-dependent promoters and upstream activation sequences. (A) The pspA promoter contains an IHF-binding site $(-30$ to -65$)$ (Weiner et al. 1995) and two high-affinity binding sites ( -89 to -126$)$ for the PspF transcriptional activator (Jovanovic 1997). The $\mathrm{glnH}$ promoter contains an IHF-binding site ( -33 to -59$)$, two overlapping high-affinity binding sites for the $N R_{1}$ transcriptional activator ( -100 to -129$)$, and two lower affinity $N R_{1}$ sites (not shown) (Claverie-Martin and Magasanik 1991). The gl $\mathrm{AAp} 2$ promoter contains two high affinity $N R_{1}$ sites ( -100 to -147$)$ as well as three weaker $N R_{1}$ sites (not shown) (Reitzer and Magasanik 1986). The pspA- $\Delta$ UAS promoter is identical to the pspA promoter except that the sequences spanning the PspF binding sites were del eted (Dworkin et al. 1997). (B) The upstream activation sequences (in bold) of the promoters schematized in A. N ote that the glnH UAS sequences are overlapping and that, whereas the $\mathrm{glnH}$ and gI IA P2 UAS sequences are similar, they both differ from the pspA UAS sequences.
\end{abstract}

hibit N R,-dependent activation of pspA. The glnA promoter contains no IHF-binding site (Fig. 1C) and thus is unaffected by IHF (Fig. 3A).

When the EBP is PspF, a similar effect of IHF is seen. In this case, the appropriate transcript is from the pspA promoter and the inappropriate transcript is from the glnH promoter. Quantification of these transcripts yields the specificity ratio of pspA : $\mathrm{glnH}$ is $3: 1$ in the absence of IHF (Fig. 3B, lane 1), and $14: 1$ in its presence (Fig. 3B, lane 2). A comparison of the pspA and $\mathrm{glnH}$ transcripts in the presence and absence of IHF demonstrates that IHF acts to increase PspF-dependent activation of pspA while simultaneously inhibiting PspF-dependent activation of $\mathrm{glnH}$.

When the PspF UAS sequences in the pspA promoter are removed, IHF inhibits PspF-dependent transcription (Dworkin et al. 1997). In a transcription reaction containing both this template (pspA $\Delta U \mathrm{US}$ ) and a gl $\mathrm{nH}$ promoter template (Fig. $3 C$ ), there is no change in the specificity ratio pspA $\triangle \mathrm{UAS}: \mathrm{glnH}$ in the presence of IHF. Thus, the effect of IHF to increase the specificity of activation is dependent on the presence of a specific UAS.

\section{Discussion}

IHF facilitates EBP-dependent activation of the weak, $\sigma^{54}$-dependent nifH promoter and at such weak promoters, EBPs that do not have an appropriate binding site properly positioned to take advantage of the IHF-generated bend are unable to activate efficiently (Santero et al . 1992). However, not all promoters regulated by IHF are weak; for example, the two promoters analyzed here, pspA and $\mathrm{gl} \mathrm{nH}$, are stronger than $\mathrm{nifH}$, and, as predicted, are less dependent on IHF (Fig. 2A,B; threefold) than
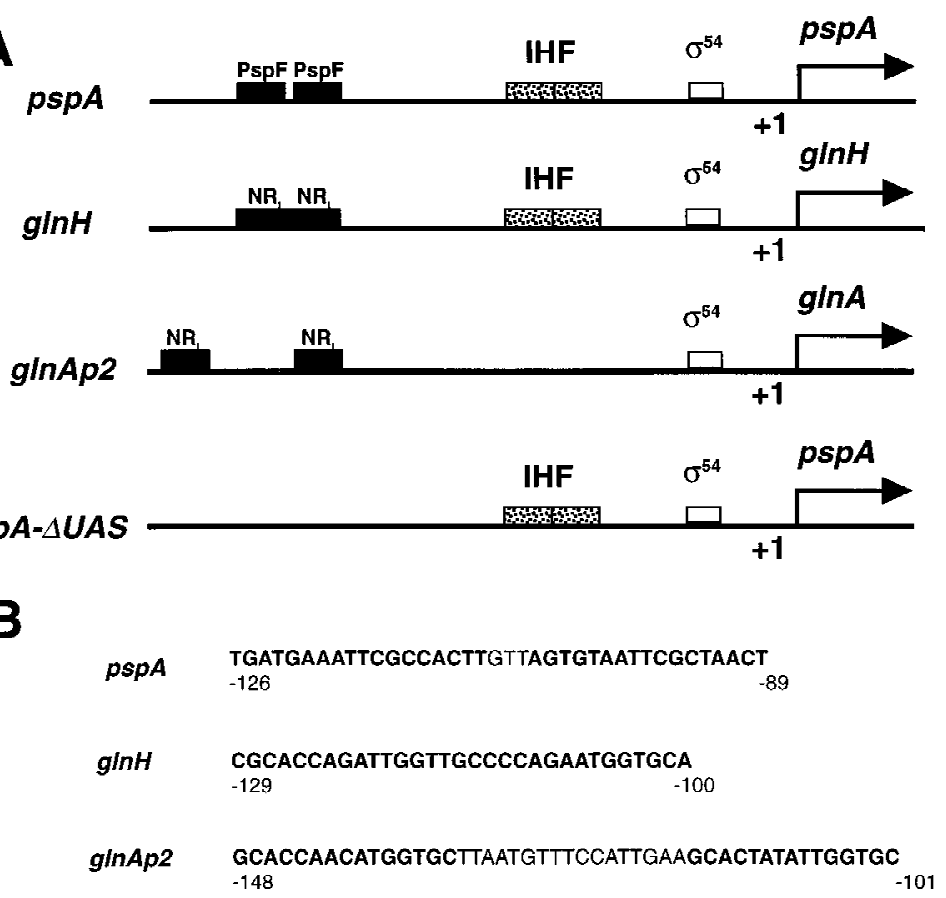

A

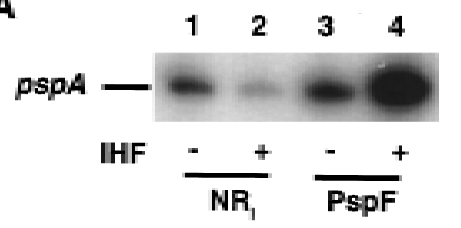

B
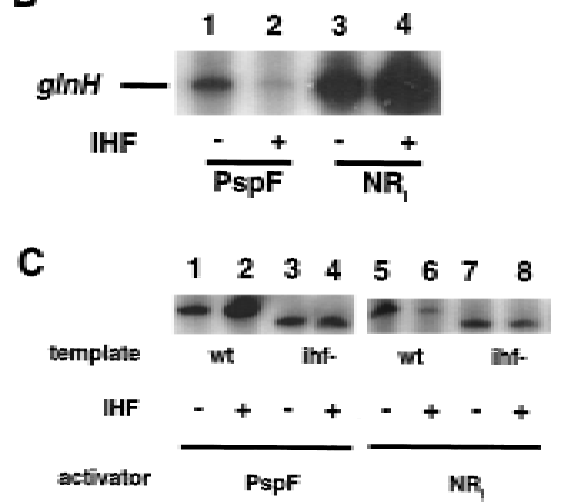

Figure 2. Effect of IHF on PspF- and $N R_{1}$-dependent in vitro transcription from pspA and gl $n \mathrm{H}$ promoters. (A) $\mathrm{NR}_{\mathrm{I}}$ - or PspFdependent activation assayed on a supercoiled pspA promoter template (pJD10) in the presence or absence of IHF. (B) PspF- or $\mathrm{NR}_{1}$-dependent activation assayed on a supercoiled $\mathrm{glnH}$ promoter template (pJD37) in the presence or absence of IHF. In the absence of any EBP, pspA- or gl $\mathrm{nH}$-specific transcription is abolished (Claverie-Martin and Magasanik 1991; Dworkin et al. 1997). (C) $N R_{1}$ - or PspF-dependent activation assayed on a supercoiled pspA promoter template (wt; pJD10) or on a supercoiled pspA promoter template lacking the IHF binding site (ihf-; pJD28). Quantified RNA transcripts (in normalized arbitrary units): (A) (Lane 1) 1.0; (lane 2) 0.19; (lane 3) 2.3; (lane 4) 6.4. (B) (Lane 1) 1.0; (lane 2) 0.41; (lane 3) 1.4; (lane 4 5.3. 


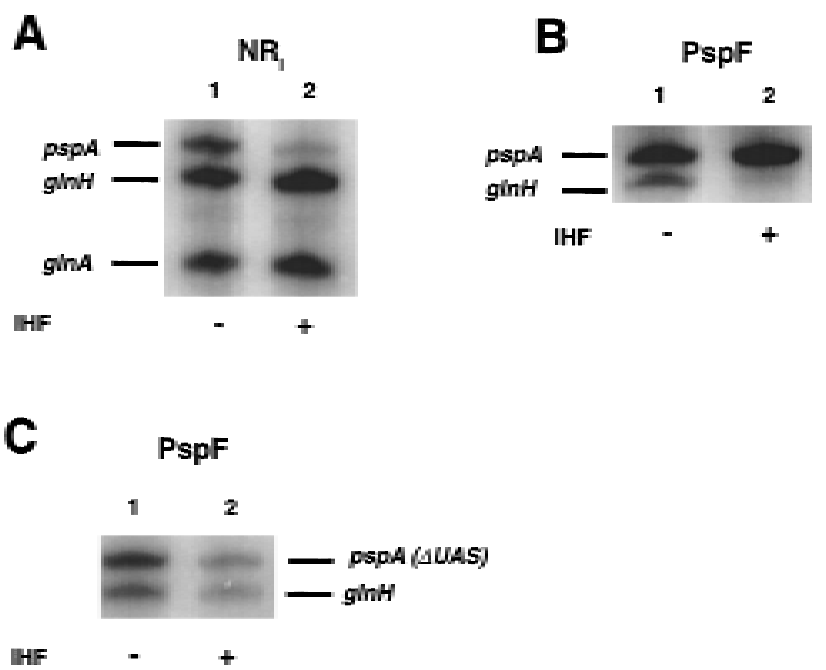

Figure 3. IHF increases specificity of activation by PspF and $N R_{1}$. (A) N $R_{1}$-dependent activation assayed on supercoiled templates (3 nm) containing the pspA promoter (pJD10), the $\mathrm{glnH}$ promoter (pJD37), and the gInA p2 promoter (pTH8) in the presence or absence of IHF. The specific transcripts generated from each of these templates are identified. (B) PspF-dependent activation assayed on supercoiled templates ( $3 \mathrm{nM})$ containing the pspA promoter (pJD10) and the gl $\mathrm{nH}$ promoter (pJD37) in the presence or absence of IHF. (C) PspF-dependent activation assayed on supercoiled templates ( $3 \mathrm{~nm}$ ) containing the pspA $\Delta$ U AS promoter (pJD12) and the gl $\mathrm{nH}$ promoter (pJD37) in the presence or absence of IHF. Quantified RN A transcripts (in decreasing order of size and in normalized arbitrary units): (A) (Lane 1) 0.61; 1.0, 0.75; (lane 2) 0.11, 1.6, 0.85; (B) (Lane 1) 1.0, 0.33; (lane 2) 1.8, 0.13; (C) (Lane 1) 1.0, 0.63; (lane 2) 0.29, 0.23.

weaker promoters (e.g., nifH, >20-fold; Hoover et al. 1990). The potential susceptibility of stronger promoters to activation by heterol ogous activators raises the question of how specificity of activation is maintained (Hoover et al. 1990; Santero et al. 1990). The experiments presented here are consistent with a model in which activation by inappropriateEBPs bound to nonspecific sites is inhibited by IHF.

While binding of proteins to upstream (or downstream) sequences can increase their effective local concentration at the promoter (M ossing and Record 1986; Rippe et al. 1995), we would argue that binding of an EBP to a nonspecific site(s) in the presence of IHF results in a DN A geometry that decreases the local concentration of the EBP near the promoter. Previous explanations of IHF inhibition of background activation have focused on the formation of a specific complex higher-order structure resulting from the relatively unique juxtaposition of several $\sigma^{54}$ promoters (Hopper et al. 1994) or on the ability of IHF to occlude access to the RNAP holoenzyme by interposing a segment of DNA that blocks interactions between an EBP acting from solution and the RNAP (de Lorenzo and Perez-M artin 1996; Perez-M artin and de Lorenzo 1995). While the data presented here do not directly eval uate the second model, heterologous EBPs, as DNA-binding proteins, can be assumed from thermody- namic principles to bind DN A nonspecifically (von Hippel et al. 1974; Lin and Riggs 1975). Further, IHF does not negatively regulate a mutant EBP lacking a DN A-binding domain (Dworkin et al. 1997).

A local ized DN A bend can have implications for DN A structure beyond its direct effect; a DN A sequence with intrinsic curvature is sufficient to determine the plectonemic structure of a supercoiled plasmid (Laundon and Griffith 1988). In fact, DN A-bending proteins that act to inhibit specific loop formation include the $\mathrm{N}$ ac protein of Klebsiella aerogenes, which prevents the interaction of $N R_{1}$ bound at a specific enhancer in the nac promoter region with the $\sigma^{54}-$ RNAP holoenzyme (Feng et al. 1995), and the CAP protein, which disrupts the repression loop formed by AraC dimers bound simultaneously to two sites in the araBAD promoter region (Lobell and Schleif 1991). Thus, the bend generated by IHF acts both to increase contacts between UAS-bound EBPs and $\sigma^{54}$ RNAP at weaker promoters and to reduce contacts be tween nonspecifical ly bound heterologous EBPs and the $\sigma^{54}$-RN AP at stronger promoters.

These observations may be particularly relevant for the regulation of eukaryotic genes, where it has been suggested that protein-protein interactions between the basal transcriptional machinery and proteins bound to distal enhancers can be modulated by the topology of the intervening DNA (Echols 1986; Ptashne 1986). In the specific case of the chicken $\beta^{A}$-globin promoter, enhancer-dependent in vitro transcription requires that the intervening DNA be supercoiled (Barton et al. 1997). Consistent with this observation, Monte Carlo-based simulations of DNA dynamics demonstrate that the effective local concentration of two sites on DNA is far greater on supercoiled DN A than on relaxed DN A (Vologodskii et al. 1992). This increase is largely unaffected by the contour separation between the sites (Vologodskii et al. 1992), suggesting that the basal transcription apparatus could be susceptible to inappropriate contacts from proteins bound at nonspecific sites located far upstream (or downstream). In vivo, where the chromosome is primarily supercoiled [and particularly upstream of promoters where transcription-induced negative supercoiling occurs (Wu et al. 1988)], mechanisms that restrict inappropriate protein-protein interactions must therefore exist.

The data presented here suggest that a general mechanism of negative regulation of loop formation may play an important role in determining the specificity of activation of promoters utilizing DNA looping. It is therefore of interest that the nucleosome appears to block access to promoters by transcription factors not by preventing binding, but instead through a distortion of the DNA structure (Luger et al. 1997).

\section{Materials and methods}

DNA manipulation

All DNA manipulations were conducted according to established protocols (Sambrook et al. 1989). All enzymes were ob- 
tained from N ew England Biolabs (Beverly, MA) unless noted. Primers were synthesized by Operon Technologies (Alameda, CA). Template DNA for in vitro transcription reactions was purified by use of either the Wizard M egaprep or M idiprep DN A purification systems (Promega).

\section{Plasmids}

pJD10 (pspA) contains a 580-bp PCR-generated fragment encompassing the pspA promoter region $(-458$ to +122$)$ cloned into the vector pGZ119EH (Lessl et al. 1992) upstream of the rnnBT 1 terminator (Dworkin et al. 1997). pJD12 (pspA $\Delta U$ AS) is identical to pJD10 except that sequences -89 to -126 were re placed with an Ndel site (Dworkin et al. 1997). pTH8 (glnAp2) contains a 600-bp Haell fragment spanning the glnA promoter region cloned into the vector pTE103 upstream of the bacteriophage T7 early terminator (Hunt and Magasanik 1985). pJD37 ( $\mathrm{glnH}$ ) was constructed by cloning the EcoRI-HindlII fragment from pFC50 (Claverie-Martin and Magasanik 1991) spanning the $\mathrm{glnH}$ promoter into the EcoRI and Hindlll sites of pGZ119EH. pJD28 (pspA -ihf) was constructed by PCR mutagenesis, which replaced the sequence -34 to -58 of the pspA promoter in pJD10 with a different sequence (5'-GGATCCTCTAGAGTCGACCTGCAG-3') of the same length not containing an IHF-binding site. Primers JD54 (5'-GGCTGGTACCTAGCGAGTTCATCAAGAAATA-3') and JD101 (5'-GGCGGATCCCTGATTGAAGAATCAACAGC-3') were used in a PCR reaction with Taq polymerase and pBRPS-1 (Brissette et al. 1991) as template. The PCR product was cleaved with BamHI and Kpnl and cloned into pGZ119EH cleaved with BamHI and Kpnl. This plasmid was cleaved with Pstl and HindIII and ligated to a fragment generated by PCR with primers JD102 (5'-GGCGGATCCCTGCAGGATAAAAAATTGGCACGCAAATTG-3') and JD103 (5'-GGCAAGCTTCAGTTTCTGTGGATCTTCC$\left.3^{\prime}\right)$, Taq polymerase, and pJD10 as template, which was then cleaved with Pstl and HindlII. The transcript from pJD28 is 28 nucleotides shorter than that from pJD10 as a result of the cloning strategy employed. The lengths of the RN A transcripts from the respective plasmids are pJD10 (pspA) $\sim 360$ nucleotides; pJD37 (glnH) 340 nucleotides; pTH8 (glnAp2) 300 nucleotides; pJD12 (pspA $\Delta$ U AS) 360 nucleotides; pJD28 (pspA -ihf) $\sim 330$ nucleotides.

\section{In vitro transcription}

Reactions were carried out in a buffer containing $50 \mathrm{~mm}$ Tris$\mathrm{HCl}(\mathrm{pH} 7.5), 50 \mathrm{~mm} \mathrm{KCl}, 10 \mathrm{~mm} \mathrm{M} \mathrm{gCl}_{2}$, and $0.1 \mathrm{~mm}$ EDTA. All reactions al so contained $0.5 \mathrm{~mm}$ GTP, $0.5 \mathrm{~mm}$ UTP, $2 \mathrm{~mm}$ ATP, $2 \mathrm{~mm}$ DTT, and 0.3 units of recombinant RN Asin (Promega). Core RN AP (Epicentre Technology, M adison WI) and $\sigma^{54}$ [purified according to Hunt and Magasanik (1985)] were added at 10 $\mathrm{nM}$ and $14 \mathrm{~nm}$, respectively. When used, PspF (gift of G. Jovanovic) was at $4 \mathrm{~nm}, \mathrm{NR}_{1}$ and $\mathrm{NR}_{\|}$[both purified according to $\mathrm{N}$ infa et al. (1987)] were at $100 \mathrm{nM}$ each, and IHF (gift of $\mathrm{H}$. $\mathrm{N}$ ash) was at $15 \mathrm{~nm}$. Typically, all components were incubated with supercoiled template $(5 \mathrm{~nm})$ at $37^{\circ} \mathrm{C}$ for $10 \mathrm{~min}$. Then $0.5 \mu \mathrm{l}$ of [ $\left.\alpha{ }^{32} \mathrm{P}\right] \mathrm{CTP}(10 \mu \mathrm{Ci} / \mu \mathrm{l}$; N ew England $\mathrm{N}$ uclear) was added [except for reactions containing $N R_{1}$ where heparin (Sigma) was added to $100 \mu \mathrm{m}$ simultaneously], and the reaction allowed to incubate $10 \mathrm{~min}$ more at $37^{\circ} \mathrm{C}$. Cold CTP was added to $1 \mathrm{~mm}$ and reaction continued at $37^{\circ} \mathrm{C}$ for $10 \mathrm{~min}$. Reactions then were placed on ice, and an aliquot was treated with phenol-chloroform and precipitated in ethanol with tRNA $(50 \mu \mathrm{g} / \mathrm{ml})$. The pellet was resuspended in RNAse-free glass-distilled $\mathrm{H}_{2} \mathrm{O}$, mixed with formamide loading buffer, loaded on $4 \%$ polyacryl- amide/ $7 \mathrm{M}$ urea gels, and run at $225 \mathrm{~V}$ in $0.5 \times \mathrm{TBE}$ as described (Sambrook et al. 1989). Gels were subjected to autoradiography or exposed to a Molecular Dynamics Storage Phosphor Screen and analyzed on a Molecular Dynamics Phosphorlmager using ImageQuant software. Quantification of Phosphorlmager data was as follows: A box was drawn around the band representing the transcription terminating at $\operatorname{rrnBT} 1$ and the pixel values were integrated. Background was calculated by integration of a same-sized box below the rrnBT 1 band in each lane and subtraction from the rrnBT 1 band.

\section{Acknowledgments}

We thank Goran Jovanovic and Howard N ash for proteins; Boris Magasanik for plasmids; Goran Jovanovic, Sydney Kustu, David Wilson, and John M arko for discussions; and M arjorie Russel for comments on the manuscript. This work was supported in part by an National Science Foundation (NSF) grant (MCB 93-16625). J.D. held an N SF Graduate Fellowship and was supported by $\mathrm{N}$ ational Institutes of Health Training Grant CA 09673-19 and by a N orman and Rosita Winston Foundation Fellowship.

The publication costs of this article were defrayed in part by payment of page charges. This article must therefore be hereby marked "advertisement" in accordance with 18 USC section 1734 solely to indicate this fact.

\section{References}

Barton, M.C., N. Madani, and B.M. Emerson. 1997. Distal enhancer regulation by promoter derepression in topologically constrained DN A in vitro. Proc. Natl. Acad. Sci. 94: 72577262.

Bellomy, G.R. and M.T. Record, Jr. 1990. Stable DN A loops in vivo and in vitro: Roles in gene regulation at a distance and in biophysical characterization of DNA. Prog. Nucleic Acid Res. Mol. Biol. 39: 81-128.

Brissette, J.L., L. Weiner, T.L. Ripmaster, and P. Model. 1991. Characterization and sequence of the Escherichia coli stressinduced psp operon. J. Mol. Biol. 220: 35-48.

Buck, M., M. Miller, M. Drummond, and R. Dixon. 1986. Upstream activator sequences are present in the promoters of nitrogen fixation genes. Nature 320: 374-378.

Buck, M., W. Cannon, and J. Woodcock. 1987. Transcriptional activation of the Klebsiella pneumoniae nitrogenase promoter may involve DNA loop formation. Mol. Microbiol. 1: $243-249$.

Busby, S. and R.H. Ebright. 1994. Promoter structure, promoter recognition, and transcription activation in prokaryotes. Cell 79: 743-746.

Claverie-Martin, F. and B. M agasanik. 1991. Role of integration host factor in the regulation of the $\mathrm{glnH}$ p2 promoter of Escherichia coli. Proc. Natl. Acad. Sci. 88: 1631-1635.

_-_. 1992. Positive and negative effects of DN A bending on activation of transcription from a distant site. J. Mol. Biol. 227: 996-1008.

de Lorenzo, V. and J. Perez-M artin. 1996. Regulatory noise in prokaryotic promoters: how bacteria learn to respond to novel environmental signals. Mol. Microbiol. 19: 11771184.

Dworkin, J. 1997. Mechanisms of transcriptional regulation of the pspA promoter of Escherichia coli. Ph.D. Thesis, Rockefeller University, N ew York, N ew York.

Dworkin, J., G. Jovanovic, and P. M odel. 1997. Role of upstream activation sequences and integration host factor in transcrip- 
tional activation by the constitutively active prokaryotic enhancer-binding protein PspF. J. Mol. Biol. 273: 377-388.

Echols, H. 1986. Multiple DN A-protein interactions governing high-precision DN A transactions. Science 233: 1050-1056.

Feng, J., T.J. Goss, R.A. Bender, and A.J. N infa. 1995. Repression of the Klebsiella aerogenes nac promoter. J. Bacteriol. 177: 5535-5538.

Gralla, J. and J. Collado-Vides. 1996. Organization and function of transcription regulatory el ements. In Escherichia coli and Salmonella: Cellular and molecular biology (ed. F. C. N eidhardt, et.al.), pp. 1232-1245. ASM Press, Washington, D.C.

Hoover, T.R., E. Santero, S. Porter, and S. Kustu. 1990. The integration host factor stimulates interaction of RNA polymerase with NIFA, the transcriptional activator for nitrogen fixation operons. Cell 63: 11-22.

Hopper, S., M. Babst, V. Schlensog, H.M. Fischer, H. Hennecke, and A. Bock. 1994. Regulated expression in vitro of genes coding for formate hydrogenylase components of Escherichia coli. J. Biol. Chem. 269: 19597-19604.

Hunt, T.P. and B. Magasanik. 1985. Transcription of glnA by purified Escherichia coli components: Core RNA polymerase and the products of $\mathrm{glnF}$, glnG, and $\mathrm{glnL}$. Proc. Natl. Acad. Sci. 82: 8453-8457.

Jovanovic, G. 1997. Activation of phage shock protein operon transcription in Escherichia coli. Ph.D. Thesis, Rockefeller University, N ew York, N ew York.

Jovanovic, G., L. Weiner, and P. Model. 1996. Identification, nucleotide sequence, and characterization of PspF, the transcriptional activator of the Escherichia coli stress-induced psp operon. J. Bacteriol. 178: 1936-1945.

Kaufman, R.I. and B.T. N ixon. 1996. Use of PCR to isolate genes encoding sigma54-dependent activators from diverse bacteria. J. Bacteriol. 178: 3967-3970.

Kustu, S., A.K. N orth, and D.S. Weiss. 1991. Prokaryotic transcriptional enhancers and enhancer-binding proteins. Trends Biochem. Sci. 16: 397-402.

Laundon, C.H. and J.D. Griffith. 1988. Curved helix segments can uniquely orient the topology of supertwisted DNA. Cell 52: 545-549.

Lessl, M., D. Balzer, R. Lurz, V.L. Waters, D.G. Guiney, and E. Lanka. 1992. Dissection of IncP conjugative plasmid transfer: Definition of the transfer region Tra2 by mobilization of the Tral region in trans. J. Bacteriol. 174: 2493-2500.

Lin, S. and A.D. Riggs. 1975. The general affinity of lac repressor for E. coli DN A: Implications for gene regulation in procaryotes and eucaryotes. Cell 4: 107-111.

Lobell, R.B. and R.F. Schleif. 1991. AraC-DN A looping: Orientation and distance-dependent loop breaking by the cyclic AM P receptor protein. J. Mol. Biol. 218: 45-54.

Luger, K., A.W. Mader, R. Richmond, D.F. Sargent, and T.J. Richmond. 1997. Crystal structure of the nucleosome core particle at 2.8 å resolution. Nature 389: 251-260.

Matthews, K.S. 1992. DNA looping. Microbiol. Rev. 56: 123136.

Model, P., G. Jovanovic, and J. Dworkin. 1997. The Escherichia coli phage shock protein operon. Mol. Microbiol. 24: 255261.

Morett, E. and L. Segovia. 1993. The sigma 54 bacterial enhancer-binding protein family: Mechanism of action and phylogenetic relationship of their functional domains. J. Bacteriol. 175: 6067-6074.

Morett, E., W. Cannon, and M. Buck. 1988. The DN A-binding domain of the transcriptional activator protein $\mathrm{N}$ ifA resides in its carboxy terminus, recognises the upstream activator sequences of nif promoters and can be separated from the positive control function of NifA. Nucleic Acids Res. 16: 11469-11488.

Mossing, M.C. and M.T. Record, Jr. 1986. Upstream operators enhance repression of the lac promoter. Science 233: 889892.

Ninfa, A.J. and B. Magasanik. 1986. Covalent modification of the glnG product, NRI, by the glnL product, NRII, regulates the transcription of the glnALG operon in Escherichia coli. Proc. Natl. Acad. Sci. 83: 5909-5913.

Ninfa, A.J., L.J. Reitzer, and B. Magasanik. 1987. Initiation of transcription at the bacterial glnA 2 promoter by purified E. coli components is facilitated by enhancers. Cell 50: 10391046.

N orth, A.K. and S. Kustu. 1997. M utant forms of the enhancerbinding protein NTRC can activate transcription from solution. J. Mol. Biol. 267: 17-36.

Perez-M artin, J. and V. de Lorenzo. 1995. Integration host factor suppresses promiscuous activation of the sigma 54-dependent promoter Pu of Pseudomonas putida. Proc. Natl. Acad. Sci. 92: 7277-7281.

Perez-M artin, J., F. Rojo, and V. de Lorenzo. 1994. Promoters responsive to DNA bending: A common theme in prokaryotic gene expression. Microbiol. Rev. 58: 268-290.

Popham, D.L., D. Szeto, J. Keener, and S. Kustu. 1989. Function of a bacterial activator protein that binds to transcriptional enhancers. Science 243: 629-635.

Ptashne, M. 1986. Gene regulation by proteins acting nearby and at a distance. Nature 322: 697-701.

Reitzer, L.J. and B. M agasanik. 1986. Transcription of glnA in E. coli is stimulated by activator bound to sites far from the promoter. Cell 45: 785-792.

Rice, P.A., S. Yang, K. Mizuuchi, and H.A. N ash. 1996. Crystal structure of an IHF-DN A complex: A protein-induced DN A U-turn. Cell 87: 1295-1306.

Rippe, K., P.H. von Hippel, and J. Langowski. 1995. Action at a distance: DNA-looping and initiation of transcription. Trends Biochem. Sci. 20: 500-506.

Rippe, K., M. Guthold, P.H. von Hippel, and C. Bustamante. 1997. Transcriptional activation via DNA-looping: Visualization of intermediates in the activation pathway of E. coli RN A polymerase $\sigma^{54}$ holoenzyme by scanning force microscopy. J. Mol. Biol. 270: 125-138.

Sambrook, J., E.F. Fritsch, and T. Maniatis. 1989. Molecular cloning: A laboratory manual, Cold Spring Harbor Laboratory Press, Cold Spring Harbor, NY.

Santero, E., T. Hoover, and S. Kustu. 1990. M echanism of transcription from nif promoters: Involvement of IHF. In Nitrogen fixation: Achievements and objectives (ed. P.H. Gresshoff, L.E. Roth, G. Stacey, and W.E. N ewton), pp. 459-466. Chapman and Hall, New York, NY.

Santero, E., T.R. Hoover, A.K. N orth, D.K. Berger, S.C. Porter, and S. Kustu. 1992. Role of integration host factor in stimulating transcription from the sigma 54-dependent nifH promoter. J. Mol. Biol. 227: 602-620.

Schleif, R. 1992. DNA looping. Annu. Rev. Biochem. 61: 199223.

Su, W., S. Porter, S. Kustu, and H. Echols. 1990. DN A-looping and enhancer activity: Association between DNA-bound $\mathrm{N}$ trC activator and RNA polymerase at the bacterial glnA promoter. Proc. Natl. Acad. Sci. 87: 5504-5508.

Vologodskii, A.V., S.D. Levene, K.V. Klenin, M. Frank-Kamenetskii, and N.R. Cozzarelli. 1992. Conformational and thermodynamic properties of supercoiled DN A. J. Mol. Biol. 227: 1224-1243.

von Hippel, P.H., A. Revzin, C.A. Gross, and A.C. Wang. 1974. $\mathrm{N}$ on-specific DN A binding of genome regulating proteins as 


\section{Dworkin et al.}

a biological control mechanism: I. The lac operon: Equilibrium aspects. Proc. Natl. Acad. Sci. 71: 4808-4812.

Wang, J.C. and G.N. Giaever. 1988. Action at a distance al ong DNA. Science 240: 300-304.

Wedel, A., D.S. Weiss, D. Popham, P. Droge, and S. Kustu. 1990. A bacterial enhancer functions to tether a transcriptional activator near a promoter. Science 248: 486-490.

Weiner, L., J.L. Brissette, and P. Model. 1991. Stress-induced expression of the Escherichia coli phage shock protein operon is dependent on $\sigma 54$ and modulated by positive and negative feedback mechanisms. Genes \& Dev. 5: 1912-1923.

Weiner, L., J.L. Brissette, N. Ramani, and P. M odel. 1995. A nalysis of cis-acting el ements regulating the stress-induced phage shock protein operon. Nucleic Acids Res. 23: 2030-2036.

Weiss, D.S., K.E. Klose, T.R. Hoover, A.K. N orth, S.C. Porter, A.B. Wedel, and S. Kustu. 1992. Prokaryotic transcriptional enhancers. In Transcriptional regulation (ed. S.L. M cKnight and K.R. Yamamoto), pp. 667-726. Cold Spring Harbor Press, Cold Spring Harbor, N ew York.

Wu, H.Y., S.H. Shyy, J.C. Wang, and L.F. Liu. 1988. Transcription generates positively and negatively supercoiled domains in the template. Cell 53: 433-440. 


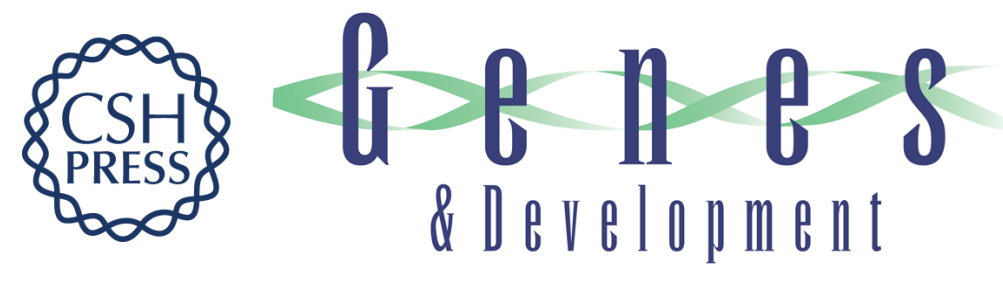

\section{A protein-induced DNA bend increases the specificity of a prokaryotic enhancer-binding protein}

Jonathan Dworkin, Alexander J. Ninfa and Peter Model

Genes Dev. 1998, 12:

References This article cites 49 articles, 21 of which can be accessed free at:

http://genesdev.cshlp.org/content/12/6/894.full.html\#ref-list-1

License

Email Alerting Receive free email alerts when new articles cite this article - sign up in the box at the top Service right corner of the article or click here.

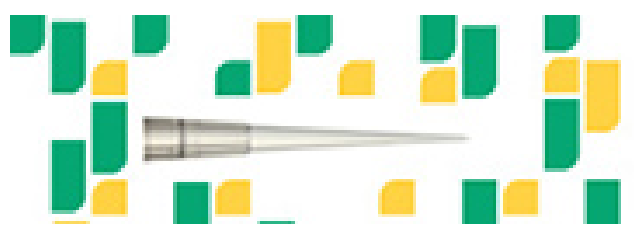

Focused on your science. 